\title{
O DISCURSO POLITICO E A CHARGE ELETRÔNICA: UMA ANÁLISE À LUZ DO INTERACIONISMO SOCIODISCURSIVO
}

\section{THE POLITICAL SPEECH AND THE ELECTRONIC CARTOON: AN ANALYSIS IN THE LIGHT OF SOCIO-DISCURSIVE INTERACTIONISM}

\author{
Lilia Santos Abreu-Tardelli*, Andressa Cristiane dos Santos**, Leticia Fonseca \\ Borges **** e Gatália Santos Ciceri***** \\ Universidade Estadual Paulista "Júlio de Mesquita Filho", São José do Rio Preto, SP, Brasil
}

\begin{abstract}
Resumo: Fundamentado no interacionismo sociodiscursivo (BRONCKART, 1999), este artigo objetiva realizar uma análise por meio do folhado textual, enfatizando as vozes e modalizaç̃oes presentes no discurso político proferido pela presidente Dilma Rousseff, na abertura da $68^{\circ}$ Assembleia-Geral da ONU. Além disso, mostraremos como essas vozes repercutem em outros textos, a partir da análise de uma charge eletrônica relativa a esse discurso. A escolha do discurso proferido pela presidente, nessa ocasião, justificase pelo destaque que recebeu da mídia brasileira, principalmente quanto à manifestação da presidente em relação à espionagem norte-americana sofrida pelo Brasil. A escolha da charge eletrônica deu-se devido ao gênero estar ligado a acontecimentos atuais, ser essencialmente crítico e polifônico (ROMUALDO, 2000) e sua significação ser construída relacionada a fatos políticos. A análise do discurso da presidente possibilitou-nos verificar como os mecanismos enunciativos contribuem para a construção de uma imagem ideológica do evento em si, de eventos políticos concomitantes e da própria presidente. Na análise da charge, apontamos a relação dialógica existente entre os textos, a partir de elementos verbais e não-verbais; e, dada à ironia característica do gênero, notamos que o texto orienta o leitor para um único ponto de vista da situação política brasileira.
\end{abstract}

Palavras-chave: Discurso político; Charge eletrônica; Interacionismo sociodiscursivo.

\begin{abstract}
Based on socio-discursive interactionism (BRONCKART, 1999), this article aims at analyzing from the concept of text layering, emphasizing voices and modalization, the political speech pronounced by Dilma Roussef in the opening of 68th UN General Assembly. In addition, it will be showed how these voices reverberate in other texts, starting from the analysis of an electronic cartoon related to this speech. The speech pronounced by the president in this occasion, is due to the fact that Brazilian media highlighted it, mainly because of the demonstration of the president in relation to north American spying that Brazil experienced. The electronic cartoon was chosen because the genre is related to current facts, essentially critical and polyphonic (ROMUALDO, 2000) and its signification is built related to political facts. The analysis of the president speech enabled us to verify how enunciative mechanisms contribute to the construction of an ideological image of the event itself, of concomitant political events and of the president. Analyzing
\end{abstract}

* Professora da Universidade Estadual Paulista "Júlio de Mesquita Filho" - UNESP, São José do Rio Preto, SP, Brasil; lilia@ibilce.unesp.br

** Mestre em Estudos Linguísticos pela Universidade Estadual Paulista "Júlio de Mesquita Filho" - UNESP, São José do Rio Preto, SP, Brasil; dessa0304@yahoo.com.br

*** Mestre em Estudos Linguísticos pela Universidade Estadual Paulista "Júlio de Mesquita Filho" - UNESP, São José do Rio Preto, SP, Brasil; leticia.borges.nh@gmail.com

***** Mestre em Estudos Linguísticos pela Universidade Estadual Paulista "Júlio de Mesquita Filho" - UNESP, São José do Rio Preto, SP, Brasil; nataliaciceri@yahoo.com.br 
Linha D'Água (Online), São Paulo, v. 29, n. 1, p. 201-224, jun. 2016

the cartoon, we point the dialogical relationship of the texts, starting from verbal and non-verbal elements; and, due to the irony, feature of the genre, we notice the text guide the reader to a single point of view of Brazilian political situation.

Keywords: Political Speech; Electronic Cartoon; Socio-Discursive Interactionism.

\section{Introdução}

Este trabalho objetiva mostrar de que maneira uma análise linguístico-enunciativa com base no quadro do interacionismo sociodiscursivo (doravante ISD) (Bronckart, 1999), principalmente em relação aos mecanismos enunciativos, possibilita uma leitura crítica em relação a qualquer texto, seja ele multimidiático ou em papel e possibilita também a compreensão da intertextualidade entre os diferentes textos midiáticos e a importância da memória discursiva na compreensão da relação entre esses textos. Escolhemos, para mostrar isso, o discurso político proferido pela presidente do Brasil, Dilma Rousseff, na abertura da 68a AssembleiaGeral da ONU, em 24 de setembro de 2013, assim como uma charge eletrônica produzida a partir desse discurso.

A nossa opção pelo discurso proferido pela presidente Dilma foi devido à sua grande repercussão na mídia brasileira, principalmente no tocante à sua manifestação em relação à espionagem norte-americana sofrida pelo Brasil. Consideramos apropriada a escolha do texto para análise, uma vez que foi amplamente divulgado e teve inúmeras manifestações contrárias e favoráveis à posição assumida no discurso em relação ao assunto em questão. Além disso, os discursos políticos estão presentes em diversos períodos de nossa História e são produzidos em diferentes situações político-ideológicas, como afirma Daher (2000). Ainda de acordo com a autora, a construção de sentidos desses textos se dá não só pelo que é exposto em palavras, mas por sua entonação, gestos, expressões faciais. Além disso, o espaço em que ocorre e o suporte utilizado são fundamentais para que os sentidos sejam construídos. Pinto (2006) afirma que a característica fundamental do discurso político é a sua necessidade de impor sua verdade a muitos e essa verdade está sempre ameaçada em um jogo de significações. Em razão disso, é dinâmico, frágil e provisório.

A escolha da charge justifica-se por ser um gênero essencialmente crítico e polifônico (ROMUALDO, 2000). É predominantemente visual e humorístico e mantém uma forte intertextualidade com personalidades, fatos e acontecimentos políticos, pois é construído a partir deles. Em razão dessa especificidade, possui limitação temporal e pode não ser compreendida sem uma explicação sobre o fato que o gerou. Nesse sentido, a charge escolhida tem uma relação intertextual com 
Linha D'Água (Online), São Paulo, v. 29, n. 1, p. 201-224, jun. 2016

o discurso da presidente. Ainda a respeito das características do gênero charge, Romualdo (op. cit.) aponta que um de seus principais aspectos é a polifonia, um jogo de vozes contrastantes e provocador de riso. É importante destacar que essa definição de charge refere-se à charge tradicional, também chamada de charge jornalística, contudo Magalhães (2006) aponta que as charges eletrônicas são produzidas tomando-se como base os mesmos objetivos das charges convencionais, que é a crítica social por intermédio do humor. $O$ principal diferencial desse tipo de charge é a instauração de um novo suporte material, a internet.

Nosso trabalho destaca, assim, a importância de se trabalhar a leitura (crítica) em sala de aula de textos de grande repercussão na mídia, apontando a relação dialógica que existe entre eles, além de ressaltar como os mecanismos enunciativos (vozes e modalizações), que compõem esses textos, são fundamentais para a compreensão das avaliações postas em cheque.

Para atingirmos nosso objetivo, apresentaremos inicialmente uma revisão do modelo de análise e produção de textos, fundamentado, principalmente, no interacionismo sociodiscursivo e, em seguida, a análise do discurso da presidente Dilma, e a análise da charge eletrônica, buscando enfatizar principalmente os índices que nos apontam as vozes presentes nos textos e as estratégias de modalização. Alguns conceitos serão também apresentados ao longo das análises por ficar aí mais significativa sua compreensão.

\section{Os níveis do folhado textual do ISD e as contribuições da Teoria Polifônica da Enunciação para a compreensão de textos}

Antes de abordarmos os níveis do folhado textual de Bronckart e, mais especificamente, os mecanismos enunciativos, é necessário que se esclareça a concepção de texto para o autor. Bronckart (1999) afirma que textos são formas de realizações empíricas, articuladas a diferentes situações de comunicação. $\mathrm{O}$ autor também afirma que toda e qualquer produção de linguagem situada, oral ou escrita, é um texto, que exibe um modo determinado de organização de seu conteúdo referencial, e é composto por frases articuladas umas às outras, de acordo com determinadas regras de composição. Ele ainda destaca a importância do contexto em que um texto é produzido, uma vez que cada texto está em relação de interdependência com as propriedades de seu contexto de produção. Além disso, os textos apresentam mecanismos de textualização e mecanismos enunciativos destinados a lhe assegurar coerência interna. 
Linha D'Água (Online), São Paulo, v. 29, n. 1, p. 201-224, jun. 2016

[Texto é] toda unidade de produção de linguagem que veicula uma mensagem linguisticamente organizada e que tende a produzir um efeito de coerência sobre o destinatário. Consequentemente, essa unidade de produção de linguagem pode ser considerada como a unidade comunicativa de nível superior. (Bronckart, 1999, p. 71)

Vale destacar que, neste artigo, fazemos a análise de um texto oral, transcrito e veiculado pela mídia nos dias subsequentes ao discurso da presidente e de um texto multimodal (charge eletrônica). No entanto, os elementos icônicos na charge eletrônica não serão analisados (cores, rosto, gesto, tom de voz etc.), pois acreditamos não serem fundamentais para nossos objetivos. No entanto, as análises aqui apresentadas podem ser complementadas por um quadro de análise que contemple essas novas formas de textualidade.

Bronckart, na obra Atividades de linguagem, textos e discursos: por um interacionismo sociodiscursivo (1999), propõe um modelo de arquitetura textual, denominado folhado textual, baseando-se na hipótese de que todo texto está organizado em três níveis que se superpõem hierarquicamente: i) nível profundo, que é a infraestrutura geral do texto e engloba o plano geral, os tipos de discurso e as sequências; ii) nível intermediário, que são os mecanismos de textualização, como os mecanismos de conexão, coesão nominal e coesão verbal; iii) nível superficial, que são os mecanismos enunciativos, divididos em vozes e modalizações.

Com relação ao primeiro nível, Bronckart propõe primeiramente uma análise do plano global do texto, isto é, do modo como se estrutura com relação à apresentação dos conteúdos temáticos. Em seguida, deve-se atentar para os tipos de discursos, formas linguísticas identificáveis nos textos que denotam a implicação ou a autonomia do agente do discurso, bem como a conjunção ou a disjunção do momento da enunciação, determinando o modo como o sujeito se posiciona com relação aos mundos representados. Identifica-se a implicação/autonomia por meio de dêiticos de pessoa, espaço e tempo, ao passo que a conjunção/disjunção é identificada por meio dos tempos verbais. Desta forma, os tipos de discurso, segundo o autor, são quatro: discurso interativo (conjunto e implicado), relato interativo (disjunto e implicado), discurso teórico (conjunto e autônomo) e narração (disjunto e autônomo). Já os tipos de sequências relacionam-se à organização sequencial ou linear do conteúdo temático, sendo divididas em seis tipos: argumentativa, descritiva, narrativa, explicativa, injuntiva e dialogal ${ }^{1}$.

Para maiores informações sobre o folhado textual, ver Bronckart (1999). 
O segundo nível, os mecanismos de textualização, responsáveis pela coerência temática do texto, visa analisar como as ideias são articuladas por meio de conectivos; além da coesão verbal, que trata da articulação dos tempos verbais e, por fim, da coesão nominal que verifica as referenciações realizadas ao longo do texto sobre elementos do conteúdo temático.

O terceiro nível do folhado trata dos mecanismos de enunciação, que contribuem para a coerência pragmática do texto, ou seja, orientam a interpretação do leitor, buscando obter sua adesão a um determinado posicionamento enunciativo. Como já foi citado anteriormente, os mecanismos que marcam textualmente esse nível são as vozes e as modalizações. No que diz respeito às vozes, o autor reconhece como primeira instância enunciativa o "autor empírico", definido como segue:

"agente da ação de linguagem que se concretiza num texto empírico, é, aparentemente, responsável pela totalidade das operações que darão a esse texto seu aspecto definitivo [...]. Portanto, tratando-se da produção de linguagem, ou produção textual, a noção de autor parece realmente corresponder à definição geral dada pelos dicionários: “aquele que está na origem” e "aquele que é responsável”. (BRONCKART, 1999, p. 320)

No entanto, mesmo admitindo uma instância que poderia ser responsabilizada por qualquer "escolha" realizada no texto, Bronckart (1999, p. 321) aponta, reconhecendo a natureza dialógica da linguagem, que "as representações do autor estão em caráter de interação com outras instâncias, que constituem outras vozes dentro do próprio discurso".

Partindo, portanto, desse reconhecimento, ele explica que o gerenciamento das vozes é realizado por uma instância geral de enunciação, que corresponderia ao narrador, ao expositor ou, ainda, a um textualizador, nomenclaturas que o autor prefere evitar. Essa instância seria responsável pela distribuição de três vozes definidas pelo autor:

(i) a voz do autor, que procede diretamente da pessoa que está na origem da produção textual;

(ii) a voz das personagens, procedentes de seres humanos ou entidades humanizadas na qualidade de agentes em um acontecimento ou ação de um segmento do texto; 
Linha D'Água (Online), São Paulo, v. 29, n. 1, p. 201-224, jun. 2016

(iii) e as vozes sociais, que são procedentes de personagens, grupos ou instituições sociais que não intervém como agentes no percurso temático, são instâncias externas da avaliação.

Embora a definição de apenas três tipos de vozes pareça simplificada, essa proposta de Bronckart dá conta de mostrar a complexidade da combinação dessas diferentes instâncias no texto. Essas combinações mostram, num sentido amplo, a existência da polifonia constitutiva de qualquer discurso:

"[...] um texto é polifônico, quando nele se fazem ouvir várias vozes distintas, podendo tratar-se de várias vozes de mesmo estatuto (diferentes vozes sociais ou diferentes vozes de personagens) ou de combinações de vozes de estatuto diferente (voz do autor, voz de um personagem, voz social, etc.). Portanto, podem existir múltiplas formas de combinações polifônicas”. (BRONCKART, 1999, p. 329)

O autor, no entanto, não aprofunda, em seu quadro, a noção de polifonia. Contudo, ele nos abre a possibilidade de dialogar com outros teóricos que possibilitam aprofundar essa questão. Buscamos, então, na Teoria Polifônica da Enunciação (DUCROT, 1987), aportes para aprofundarmos a análise das vozes. Ao contrário de Bronckart, Ducrot não reconhece o autor empírico e imputa a responsabilidade do enunciado ao locutor. Essa entidade discursiva é diferenciada da noção de enunciador que, segundo ele, são seres

considerados como se expressando através da enunciação, sem que para tanto se lhe atribuam palavras precisas; se eles 'falam' é somente no sentido em que a enunciação é vista como expressando seu ponto de vista, sua posição, sua atitude, mas não, no sentido material do termo, suas palavras. (DUCROT, 1987, p. 192).

Dessa distinção, Ducrot define dois tipos de polifonia, aquela em que os posicionamentos dos locutores são apresentados no texto de maneira explícita (por meio do discurso direto, por exemplo) e aquela que permite notar, em um enunciado, a existência de mais de um enunciador, que representam pontos de vista diferentes, aderidos ou não pelo locutor em seu discurso. Para exemplificar o segundo caso de polifonia, pensemos em um enunciado como "Mariana é ainda mais inteligente que Isabela", nesse caso, o uso de ainda faz manifestar pelos menos duas vozes, uma que reconhece a inteligência de Isabela, ou seja, E1: "Isabela é inteligente"; e outra que, na comparação, ressalta a inteligência de Mariana, ou seja, E2: "Mariana é mais inteligente que Isabela". 
Baseando-se nos estudos de Ducrot e em casos como esse, Koch, Bentes e Cavalcante (2007, p. 80-83) apontam as seguintes formas linguísticas como índices da presença de outras vozes no texto: negação; marcadores de pressuposição (como certos usos dos vocábulos ainda, agora, já); verbos indicadores de mudança ou permanência de um estado anterior; determinados operadores argumentativos (como ao contrário, pelo contrário); futuro do pretérito com valor de metáfora temporal; operadores concessivos; operadores conclusivos; aspas e algumas expressões como parece que, dizem que.

Ainda como marca da "presença do outro nos jogos de linguagem", as autoras diferenciam polifonia de intertextualidade, mas lembram que, num sentido mais amplo, a intertextualidade constitui um tipo de polifonia. Elas dizem que a intertextualidade se difere da polifonia pela presença de um intertexto, e defendem que a intertextualidade também é um elemento constitutivo do texto, responsável pelos diversos tipos de relações que os textos mantêm entre si.

Segundo Koch (1997), essas relações intertextuais podem se dar de maneira explícita ou implícita. Quando há citação da fonte do texto base (intertexto) temse um caso de intertextualidade explícita como, por exemplo, em citações e referências. Quando isso não ocorre, cabe ao interlocutor recuperar o intertexto para a construção do sentido e tem-se a intertextualidade implícita. Aprofundamos os conceitos e as categorias analíticas de vozes trazidos por esses autores por ser esse o foco de análise que faremos da charge eletrônica. Passaremos, a seguir, ao conceito de modalização, parte constituinte dos mecanismos enunciativos na proposta de análise do ISD.

\section{As modalizações e os mundos representados}

Antes de falarmos das modalizações, é necessário que se faça uma introdução a respeito da noção de mundos representados, desenvolvida por Habermas, que afirma que para se desenvolver uma atividade, os interactantes devem partilhar de alguns conhecimentos pertencentes a três ordens que definem os mundos objetivo, social e subjetivo. As atividades de linguagem serão avaliadas a partir das características desses mundos, de modo que os humanos construirão, por meio de negociação, as coordenadas formais desses mundos que regem e contextualizam suas atividades. Devido ao seu estatuto de formas negociadas, os signos têm uma dimensão transindividual, veiculando representações coletivas do meio, estruturadas em configurações de conhecimento que são chamadas de mundos representados (Bronckart, 1999, p. 33).

Em relação ao mundo objetivo, é possível afirmar que os signos remetem a aspectos do meio físico e permitem as representações feitas sobre os parâmetros do 
Linha D'Água (Online), São Paulo, v. 29, n. 1, p. 201-224, jun. 2016

ambiente. No mundo subjetivo, os signos incidem sobre as características próprias de cada um dos indivíduos engajados na tarefa. No que diz respeito ao mundo social, os signos incidem sobre a maneira de organizar a tarefa, sobre as modalidades convencionais de cooperação entre os membros do grupo, além de incidirem sobre o conhecimento de uma pessoa em relação às regras sociais de determinados grupos. É interessante destacar que é o mundo social que condiciona as formas de estruturação do mundo subjetivo e do mundo objetivo.

Em resumo, o conhecimento que se tem sobre aspectos físicos e sociais envolvidos na situação de interação, e o objetivo que se tem com essa interação é o que permite mobilizar o que for necessário para que se atinja o objetivo. Tal afirmação é corroborada por Silva, ao afirmar que:

uma determinada interação verbal, o produtor, ao produzir seu texto mobiliza seus conhecimentos sobre os mundos representados: sobre a atividade na qual será realizada a sua produção, as pessoas envolvidas, o que se espera socialmente dele nessa atividade e o que ele acredita ser necessário fazer, os conhecimentos internalizados construídos por sua interação com o meio ao longo da vida e o conhecimento que tem sobre a língua. (2009, p. 34)

Os conhecimentos mobilizados pelos mundos representados refletem-se nas modalizações presentes nos textos, sendo elas formas de posicionamento enunciativo por meio do qual se expressam avaliações, opiniões, julgamentos e comentários proferidos pelas instâncias comunicativas, isto é, pelas vozes, com relação ao conteúdo temático apresentado. Bronckart (1999) divide as modalizações quatro tipos: lógica, deôntica, apreciativa e pragmática.

$\mathrm{O}$ autor afirma que as modalizaçóes lógicas relacionam-se aos critérios do mundo objetivo, isto é, aos signos que remetem a aspectos físicos, e exprimem julgamentos sobre a veracidade daquilo que é enunciado, apresentando os aspectos do conteúdo temático como certos, possíveis, prováveis, improváveis, necessários e etc. Tais modalizações apresentam-se por meio de tempos verbais na condicional, auxiliares e orações impessoais, tais como: é evidente que, é improvável que, certamente, evidentemente, entre outras.

As modalizaçóes deônticas, segundo o autor, relacionam-se aos critérios do mundo social, isto é, às relações interpessoais, às interações reguladas; e exprimem julgamentos ligados a valores sociais, apresentando os enunciados como socialmente permitidos, proibidos, desejáveis e necessários. Este tipo de modalização é feito por meio de tempos verbais no condicional, advérbios, auxiliares e orações impessoais, como: é preciso que, é necessário que, etc.; e poder, ser obrigado a, dever etc. 
Outro tipo de modalização são as modalizaçôes apreciativas que se relacionam aos critérios do mundo subjetivo, aquele em que há manifestações de vivências e das características próprias de cada indivíduo, e servem para fazer avaliações de alguns aspectos do conteúdo temático, classificando-os como bons, ruins, estranhos, maus, do ponto de vista da instância avaliadora. São preferencialmente marcadas por advérbios ou orações adverbiais como: felizmente, infelizmente, é lamentável, etc; além de orações impessoais regidas por oração subordinada completiva (BRONCKART, 1999, p. 333).

A última modalização determinada por Bronckart é a modalização pragmática, que está relacionada tanto a aspectos do mundo subjetivo quanto do social. É interessante destacar que tais mundos muitas vezes se articulam, e portanto não é fácil a sua distinção. Como explica Pérez (2009, p. 51), as modalizações pragmáticas exprimem julgamentos relacionados à capacidade de ação (poder-fazer), uma intenção (o querer fazer) e as razões (o dever-fazer) atribuídas a um agente. Estas modalizações são, preferencialmente, marcadas pelos auxiliares de modo querer, poder, dever, ser necessário, etc.

É importante destacar que, para Bronckart, as funções das modalizações independem do tipo de discurso, porém dependem do gênero textual empregado, já que alguns textos apresentam muitas modalizações ao passo que em outros elas serão raras ou ausentes. $\mathrm{O}$ autor aponta também a existência do grau zero da modalização, isto é, quando um texto não apresenta nenhum tipo de modalização, como em obras enciclopédicas e manuais científicos. Já nos artigos científicos, manuais de história e panfletos políticos, por exemplo, o autor afirma que as modalizações podem ser frequentes, uma vez que elementos do conteúdo temático são objetos de discussão, debate e avaliação.

Após essa breve apresentação do folhado textual e, principalmente da definição do conceito de vozes e modalizações, que compõem os mecanismos enunciativos, apresentaremos as análises do discurso político e da charge eletrônica. Destacaremos, com a análise, como algumas questões são avaliadas pela presidente, e as vozes que se fazem presente tanto em seu discurso quanto na charge eletrônica, que surgiu como consequência do discurso político, evidenciando, assim, que os textos compõem-se de outros discursos que os influenciam e muitas vezes o atravessam.

\section{Análise do discurso da Presidente Dilma Rouseff na ONU em 2013}

Tendo como um de seus pressupostos que a língua é sócio-histórica e está implicada em um contexto ideológico, materializando-se entre indivíduos socialmente organizados por meio de enunciados (CRISTOVÃO, 2009, p. 41) construídos na 
Linha D'Água (Online), São Paulo, v. 29, n. 1, p. 201-224, jun. 2016

interação entre leitor, texto e seu contexto sócio-histórico, o interacionismo sociodiscursivo entende que o sentido de um texto é determinado pelas condições de produção que o envolvem e o suporte em que circula.

Dessa maneira, como veremos na análise do discurso da presidente Dilma na Assembleia da $\mathrm{ONU}^{2}$ e da charge eletrônica ${ }^{3}$ produzida após este evento, o levantamento do contexto sócio-histórico de produção desses textos é essencial para o entendimento do modo como eles se articulam, das escolhas linguísticas que os compõem e da verificação das vozes e das modalizações neles presentes.

Dessa maneira, para determinarmos o contexto sociointeracional mais amplo, devemos levar em conta os acontecimentos que estavam ocorrendo no mês de setembro de 2013 e principalmente nos meses anteriores, tais como as manifestações sociais iniciadas em junho de 2013 em todo o país, por motivos diversos e muitas vezes não explicitados; alguns dos motivos divulgados foram: o aumento nas tarifas dos transportes públicos nas grandes cidades, a violência policial, os gastos excessivos com a Copa do Mundo e as Olimpíadas, a má qualidade dos serviços públicos e a indignação com a corrupção política. Nesta mesma época, Edward Snowden, ex-funcionário da CIA, revelou ao mundo o esquema de espionagem norte-americana em vários países, dentre eles o Brasil. Outro acontecimento que antecedeu o discurso foi o atentando terrorista a um shopping ocorrido dias antes da Assembleia em Nairóbi, capital do Quênia, totalizando vinte mortos. Esses acontecimentos são importantes para interpretarmos não só a análise do discurso da presidente, como também a da charge, pois toda leitura de um texto, nessa perspectiva, envolve a compreensão de acontecimentos e eventos do contexto sociointeracional mais amplo que antecedem o próprio texto.

Com relação ao contexto de produção do discurso proferido na Assembleia da ONU, tem-se como emissor físico a presidente Dilma Roussef, cujo papeis sociais são de primeira mulher na presidência do Brasil, de ex-militante contra a ditadura militar e de pertencente ao Partido dos Trabalhadores, sucedendo o ex-presidente Luiz Inácio Lula da Silva. Como interlocutores físicos, havia 193 representantes dos Estados-Membros da ONU e a imprensa ali presente, ao passo que como interlocutores sociais têm-se políticos e a mídia do mundo todo. Com

2 Discurso completo disponível em: <http://www2.planalto.gov.br/imprensa/discursos/discurso-da-presidenta-da-republica-dilma-rousseff-na-abertura-do-debate-geral-da-68a-assembleiageral-das-nacoes-unidas-nova-iorque-eva. >. Acesso em 15 jun. 2014. Versão em vídeo disponível em <https://www.youtube.com/watch? v=bmVh9Uhf-Ns>. Acesso em: 30 set. 2014.

3 Charge disponível em <http://charges.uol.com.br/2013/09/25/cotidiano-espionagem-e -roubo/>. Acesso em: 30 set. 2014. 
Linha D'Água (Online), São Paulo, v. 29, n. 1, p. 201-224, jun. 2016

relação ao lugar de produção, o discurso aconteceu na sede da ONU em Nova Iorque, no dia 24 de setembro de 2013 em uma assembleia que visava à discussão sobre a implementação dos objetivos de Desenvolvimento do Milênio e do desenvolvimento para pessoas com deficiência; o desarmamento nuclear e o diálogo sobre Migração Internacional e Desenvolvimento. Faz-se importante destacar que a presidente brasileira foi a primeira a discursar nessa Assembleia, seguida do presidente norte-americano Barack Obama, a quem ela dirigiu boa parte dos comentários feitos. Todo esse levantamento sócio-histórico se faz relevante, pois marca o posicionamento adotado pela presidente desde o início de sua fala, como veremos adiante, na análise dos níveis que compõem o folhado textual.

\section{Primeiro nível: infraestrutura geral do texto}

Como primeira parte do folhado textual, a infraestrutura geral do texto, tem-se a análise de seu plano global, bem como os tipos de discurso e sequências empregados. Com relação ao plano global, os temas apresentados ao longo do discurso pela presidente em um primeiro momento foram, nesta ordem: cumprimento ao presidente e secretário-geral das Nações Unidas, bem como aos chefes de estado e de governo ali presentes, expressão de satisfação por ter um representante de Antígua e Barbuda entre os membros da bancada principal e oferecimento de apoio ao país, repúdio contra o atentado terrorista em Nairóbi e oferecimento de condolências ao país em nome do seu governo e do povo brasileiro e posicionamentos a favor do combate ao terrorismo. Logo depois, a presidente chama a atenção do presidente da Assembleia para apresentação do fato de espionagem ocorrido, seguida da repercussão da espionagem no Brasil, menção à ilegalidade do ato e justificativa dada para a espionagem. Em seguida, apresentação do posicionamento do Brasil quanto ao abrigo a terroristas, referência ao seu passado como ex-militante, retomando a gravidade do caso apresentado e fazendo um pedido de retratação dos Estados Unidos, evidenciando a não aceitação do fato por se tratarem de nações amigas. Logo após, a presidente menciona a proteção brasileira contra novos ataques, afirmando que as tecnologias não podem ser usadas como arma de guerra e pede por um posicionamento da ONU. Enfim, conclui apresentando a proposta brasileira para o uso da internet e proteção de dados. O plano global do discurso evidencia um posicionamento protecionista em relação aos menos favorecidos e direciona a argumentação da presidente na direção de combate a atos agressores, como a espionagem feita no Brasil pelo governo americano, como se pode ver pelo plano global dos temas: satisfação da presença de representante de Antígua e Barbuda e oferecimento de apoio ao país, manifestação de repúdio contra o atentado 
Linha D'Água (Online), São Paulo, v. 29, n. 1, p. 201-224, jun. 2016

terrorista em Nairóbi e oferecimento de condolências ao país, seguindo-se, então, o tema da espionagem no país.

Ainda em relação à infraestrutura geral dos textos, o folhado textual compreende os tipos de discurso e as sequências. No discurso em questão, predominam o discurso interativo e o discurso teórico.

O discurso interativo, marcado pela implicação dos participantes e concomitância com o momento de produção, se faz presente nos momentos em que a presidente se dirige aos membros da ONU e posiciona-se com relação ao fato ocorrido, às violações sofridas e as ações a serem tomadas. Como se pode verificar no seguinte trecho pela presença de verbos e pronomes nas primeiras pessoas do singular e plural, marcadores dêiticos e "verbos predominantemente no presente do indicativo":

“[...] Senhor Presidente/ Quero trazer à consideração das delegações uma questão a qual "atribuo" a maior relevância e gravidade".

Já o discurso teórico foi usado predominantemente nos trechos em que a presidente menciona direitos e deveres de um país e também ao mencionar princípios a serem estabelecidos para evitar que o fato se repita. Este tipo de discurso é marcado pela ausência de referência aos participantes da interação, bem como ao espaço e tempo da ação, por frases declarativas e presente genérico e certos verbos modais como pode, poderia, deve (BUTLER, 2009, p. 36). Como no exemplo que segue:

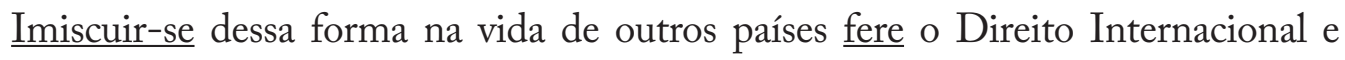
afronta os princípios que devem reger as relações entre eles, sobretudo, entre nações amigas. Jamais pode uma soberania firmar-se em detrimento de outra soberania. Jamais pode o direito à segurança dos cidadãos de um país ser garantido mediante a violação de direitos humanos e civis fundamentais dos cidadãos de outro país.

Para completar a análise da infraestrutura do texto, deve-se atentar também aos tipos de sequência presentes e, no caso desse texto analisado, encontra-se predominantemente a sequência argumentativa. A sequência argumentativa, segundo Machado (2005, p. 246), visa a "convencer o destinatário da validade do posicionamento do produtor diante de um objeto de discurso visto como contestável”, pode ser encontrada no início do discurso em que a presidente apresenta o fato da espionagem e sua gravidade; e em seguida apresenta argumentos com relação à afronta representada pela espionagem para, então, contra-argumentar afirmando que seu governo fará o que for necessário para proteger o país e novos acontecimentos como esse. Os tipos de discurso predominantes (interativo e teórico) assim como 
Linha D'Água (Online), São Paulo, v. 29, n. 1, p. 201-224, jun. 2016

a sequência argumentativa apontam na direção já vislumbrada no plano global do texto: a de um posicionamento protetor e fortemente defensor e argumentativo para se posicionar contra a espionagem no país.

\section{Segundo nível: mecanismos de textualização}

A segunda parte do folhado textual refere-se aos mecanismos de textualização, marcados principalmente pelos mecanismos de conexão, coesão verbal e coesão nominal.

No que se refere aos mecanismos de conexão, as relações estabelecidas entre as ideias apresentadas no discurso político não são interligadas por meio de conectivos. Optou-se, principalmente, pela união de ideias por meio de estruturas como sujeito-verbo. Por exemplo, é possível perceber que ao longo do discurso analisado, os discursos interativos iniciam-se pela estrutura sujeito-predicado e, em alguns casos, por vocativos, como se pode perceber pelo exemplo:

"O Brasil, senhor presidente, sabe proteger-se. Repudia, combate e não dá abrigo a grupos terroristas".

"Estamos, senhor presidente, diante de um caso grave de violação dos direitos humanos e das liberdades civis (...)”.

No contexto geral do texto, o vocativo para se referir ao presidente dos Estados Unidos reforça o significado da forte predominância do discurso interativo colocando o presidente como seu principal interlocutor.

Com relação à coesão nominal, pode-se perceber ao longo do discurso muitas referências ao ato de espionagem norte-americana. Tais referências mostram o ponto de vista da presidente com relação ao fato, e na tentativa de levar os ouvintes, dentre eles o presidente americano mencionado nos diversos vocativos utilizados, à adoção de seu posicionamento, refere-se a ele das seguintes maneiras: "intercepção ilegal", "objeto de interceptação", "estar na mira da espionagem", "imiscuir-se dessa forma na vida de outros países", "invasão e captura de informações sigilosas" e "ações ilegais".

Ao se referir ao seu país e ao seu mandato, a presidente faz uso dos termos "Brasil”, "própria presidência da República", "país democrático", "meu país”, usado duas vezes e "meu governo".

Vale destacar neste aspecto a forte influência de escolhas lexicais que remetem a guerra, a combate, como em "alvo", "mira", "terrorismo", "violação", "arma de 
guerra" e "ataque". Esses termos aparecem nos contextos em que se refere à ação da espionagem por parte do governo norte-americano.

Sobre a coesão verbal, o tempo verbal que predomina no discurso é o presente do indicativo usado quando a presidente se refere à afronta causada pela espionagem, ao Brasil ser uma nação respeitosa, a não-aceitação do caso e ao pedido de um posicionamento da ONU. Outros tempos que podem ser encontrados são pretérito perfeito, que foi utilizado para se referir às esferas que sofreram a interceptação, ao seu passado como ex-militante; e o futuro do presente ao se referir às medidas que serão tomadas pelo país para combater a ação sofrida. A análise evidenciada até o momento mostra a construção de uma memória intratextual, que remete sempre a um enunciado precedente, e o leitor-interlocutor pode reconstruir essas cadeias remissivas ao longo de todo o texto.

\section{Terceiro nível: mecanismos enunciativos}

$\mathrm{Na}$ última parte do folhado textual proposto por Bronckart, relativa aos mecanismos enunciativos, o estudo das vozes e das modalizações no discurso revelou que as vozes encontradas remetem-se à voz da autora e em alguns casos à voz social, esta exprimindo diferentes papeis ao longo do discurso. A voz da autora pode ser encontrada tanto na primeira pessoa do singular, como na primeira pessoa do plural, como se pode ver em

(1) "Quero trazer à consideração das delegações uma questão a qual atribuo a maior relevância e gravidade";

(2) "No Brasil, a situação foi ainda mais grave, pois aparecemos como alvo dessa intrusão”.

No primeiro caso, a voz que predomina é exclusivamente a da presidente do país ciente de toda a importância do momento em que o discurso fora proferido e também do poder a ela dado enquanto exerce essa função. No segundo caso, a voz é a da presidente, porém se colocando como pertencente a um grupo de pessoas que foi espionado.

A voz social pode ser encontrada no trecho "Somos um país democrático, cercado de países democráticos, pacíficos e respeitosos do Direito Internacional. Vivemos em paz com os nossos vizinhos há mais de 140 anos" em que se percebe a voz da nação, de todo o país e não mais única e exclusiva da presidente. $\mathrm{Na}$ frase "Jamais pode o direito à segurança dos cidadãos de um país ser garantido mediante a violação de direitos humanos e civis fundamentais dos cidadãos de outro país", 
Linha D'Água (Online), São Paulo, v. 29, n. 1, p. 201-224, jun. 2016

percebe-se a voz de um discurso jurídico explicando a proibição da violação dos direitos humanos e civis.

Outro aspecto a ser analisado nos mecanismos enunciativos diz respeitos às modalizações, que servem para exprimir julgamentos, sentimentos, avaliações e opiniões.

Os quatro tipos de modalizações podem ser encontrados no discurso analisado, como se pode ver nos exemplos apresentados a seguir. As modalizaçóes lógicas que avaliam o valor de verdade do conteúdo temático apresenta os fatos como certos, possíveis e prováveis, como no exemplo abaixo:

Governos e sociedades amigas, que buscam consolidar uma parceria efetivamente estratégica, como é o nosso caso, não podem permitir que ações ilegais, recorrentes, tenham curso como se fossem normais.

As modalizaçôes deônticas que, segundo Peréz, (2009) avaliam alguns elementos do conteúdo temático com base em valores sociais, apresentando-os como permitidos, proibidos, necessários e desejáveis, como exemplificadas no trecho:

Imiscuir-se dessa forma na vida de outros países fere o Direito Internacional e afronta os princípios que devem reger as relações entre eles, sobretudo, entre nações amigas. Jamais pode uma soberania firmar-se em detrimento de outra soberania;

Com relação à modalização pragmática, que atribui a um agente intenções, razões e capacidades de ação, pode ser encontrada no trecho:

Como tantos outros latino-americanos, lutei contra o arbítrio e a censura e não posso deixar de defender de modo intransigente o direito à privacidade dos indivíduos e a soberania de meu país;

A última modalização, a apreciativa, exprime uma avaliação do conteúdo temático classificando-o como bom, ruim, estranho, do ponto de vista da instância avaliadora (PERÉZ, 2009), pode ser encontrada em

Pior ainda quando empresas privadas estão sustentando essa espionagem.

Todas as modalizações presentes no discurso e exemplificadas aqui mobilizam o discurso na direção argumentativa de todo o texto: contra a espionagem americana no país. 
Linha D'Água (Online), São Paulo, v. 29, n. 1, p. 201-224, jun. 2016

Após a análise do discurso político segundo o modelo do folhado textual de Bronckart (1999), a próxima seção analisará as vozes presentes na charge eletrônica. Analisaremos, numa relação intertextual, como a imagem e o discurso da presidente se alteram a fim de fazer notar uma crítica à situação política brasileira.

\section{Análise das vozes e modalizações da charge}

A escolha do gênero charge, neste artigo, resulta da necessidade que tivemos de esclarecer como se dá a relação dialógica entre textos, com o objetivo de exemplificar casos de intertextualidade. Como partimos da análise de um discurso político, consideramos coerente a seleção desse gênero, que se caracteriza pela "crítica humorística de um fato ou acontecimento específico, em geral de natureza política" (RABAÇA; BARBOSA, 1978, p. 89 apud ROMUALDO, 2000, p. 21).

Dessa maneira, analisamos a charge eletrônica, destacando os mecanismos enunciativos, pois fica evidente que nesse texto específico, a presença das vozes tem uma forte influência para remeter o leitor à memória interdiscursiva, tal como apresentada por Moirand (MOIRAND, 1999 apud CHARAUDEAU \& MAINGUENEAU, 2004). Segundo o autor, a memória interdiscursiva se constrói "na e pela mídia" sobre os acontecimentos e formulações recorrentes, remetendo a discursos anteriores, no nosso caso, remetendo o leitor não só ao discurso da presidente, mas ao que a própria mídia pôs em evidência ao noticiar o discurso proferido. A charge eletrônica em foco foi publicada no site da UOL, cuja fonte é o discurso da presidente Dilma.

Sendo assim, as vozes encontradas revelam um jogo conflitante, como se pode verificar nos exemplos organizados no quadro a seguir: 
Linha D'Água (Online), São Paulo, v. 29, n. 1, p. 201-224, jun. 2016

\begin{tabular}{|c|c|c|}
\hline TRECHO & RECURSO LINGUÍSTICO & VOZ \\
\hline $\begin{array}{l}\text { 1- "Não temos medo de que o } \\
\text { conteúdo vaze porque estou certa } \\
\text { de que não acharão nada que nos } \\
\text { incrimine" }\end{array}$ & Negação & $\begin{array}{l}\text { Voz implícita indicando } \\
\text { que há o medo do } \\
\text { vazamento do conteúdo e, } \\
\text { consequentemente, indícios } \\
\text { de crime }\end{array}$ \\
\hline $\begin{array}{c}\text { 2- "Político brasileiro é experien- } \\
\text { te o suficiente para se expressar } \\
\text { com frases como: falei com ele } \\
\text { lá e já tá acertada aquela parada. } \\
\text { A divisão fica no esquema de } \\
\text { sempre...”. }\end{array}$ & Discurso direto & Voz do corrupto \\
\hline $\begin{array}{l}\text { 3- "o que fora do contexto não } \\
\text { quer dizer nada!" }\end{array}$ & & Voz em defesa do corrupto \\
\hline $\begin{array}{l}\text { 4- "O dano é moral porque todos } \\
\text { sabem que não existem terroristas } \\
\text { estrangeiros escondidos no Brasil" }\end{array}$ & Negação & $\begin{array}{c}\text { Voz implícita, que } \\
\text { contrasta com a negação } \\
\text { e apresenta a afirmação } \\
\text { de que existem terroristas } \\
\text { estrangeiros escondidos em } \\
\text { nosso país. }\end{array}$ \\
\hline 5- “Companheira, eu não sabia!”. & Discurso direto & $\begin{array}{l}\text { Voz do ex-presidente } \\
\text { Lula com a frase muito } \\
\text { proferida durante os } \\
\text { escândalos do Mensalão. }\end{array}$ \\
\hline
\end{tabular}

\section{Quadro 1}

O quadro mostra que à voz da personagem, que representa a presidente da república, estão imbricadas outras vozes, como a voz do corrupto e vozes implícitas que indicam posicionamentos contrários ao que ela defende no discurso proferido. Esse jogo de vozes constrói uma imagem diferente daquela construída na ocasião do discurso da ONU e isso só é possível devido à memória que o leitor/ouvinte tem de outros discursos midiáticos sobre a presidente, o partido a que pertence e o político brasileiro.

$\mathrm{Na}$ charge, devido à polifonia presente em seu discurso, a imagem da presidente sofre uma transgressão, passando a ser representada como adepta à corrupção e, por isso, cautelosa em relação às questões referentes à espionagem, como mostram os trechos (1) e (4), no quadro.

Dessa maneira, o humor que a charge procura provocar emerge de um conflito de vozes que aparece com o objetivo de estampar na fala da presidente outras questões que não foram por ela levantadas, tais como a corrupção atribuída a seu 
partido, colocando-a como protagonista responsável por carregar com ela essas outras posições enunciativas. O discurso original sofre, portanto, uma transgressão e o humor da charge é justamente construído não pelo repertório cultural e o conhecimento do acontecimento e do texto-fonte parodiados por parte do leitor, ou seja, não a cargo de uma "memória individual", mas é principalmente percebido pelo leitor, nos sentidos entrecruzados da memória social construída e dos implícitos presentes, ou seja, os pré-construídos, discursos-transversos, elementos citados e relatados (ACHARD, P. et al. 2010). Essa transgressão também é perceptível no caso da charge, não só pelos elementos linguísticos que evocam e alteram o discurso da presidente Dilma, mas também pelos elementos não-verbais que compõem a charge, tais como a construção caricatural de uma personalidade, a representação pictórica do lugar de onde ela fala, a presença do símbolo da ONU e ainda a mudança de entonação. Romualdo (2000, p. 26-27) explica que a caricatura é um elemento constituinte da charge e que consiste na deformação de "características marcantes do indivíduo." Essa deformação gera uma imagem humorística que pode valorizar os aspectos positivos de uma personalidade, ou ridicularizá-la, destacando seus traços negativos.

Segundo o autor, esse destaque a traços mais marcantes carrega a imagem de subjetividade e leva o leitor a reconhecer as "informações subjacentes" e a formar um juízo de valor sobre elas. O recurso, no entanto, não tem eficácia se o leitor não conhece a personalidade caricaturada ou o fato político referido na charge. Para Romualdo, isso ressalta a relevância dos contextos.

O autor explica, com base em Cagnin (1975), que para compreendermos uma charge, em sua totalidade, precisamos relacioná-la a três tipos de contextos: o intra -icônico, definido pelas relações entre os elementos que compõem uma figura; o intericônico, relativo à sequencialidade das imagens, no caso da charge, uma sequência narrativa; e o contexto extra-icônico, que engloba o contexto situacional, associado ao ato comunicativo, e o contexto global de ordem cultural e espaço-temporal.

É interessante notar que a relação dialógica presente entre os textos em análise se manifesta, principalmente, por uma relação intertextual que ultrapassa os limites do material linguístico. O humor, na charge, é dado não só por meio da subversão do discurso da presidente Dilma, mas também pela representação pictórica e, em certa medida parodiada, de seus trejeitos, de seus traços mais marcantes, de sua vestimenta, da representação do lugar de onde ela fala; ou seja, o não-verbal opera, assim como o verbal, na relação entre os textos e na produção dos sentidos pretendidos. 
Linha D'Água (Online), São Paulo, v. 29, n. 1, p. 201-224, jun. 2016

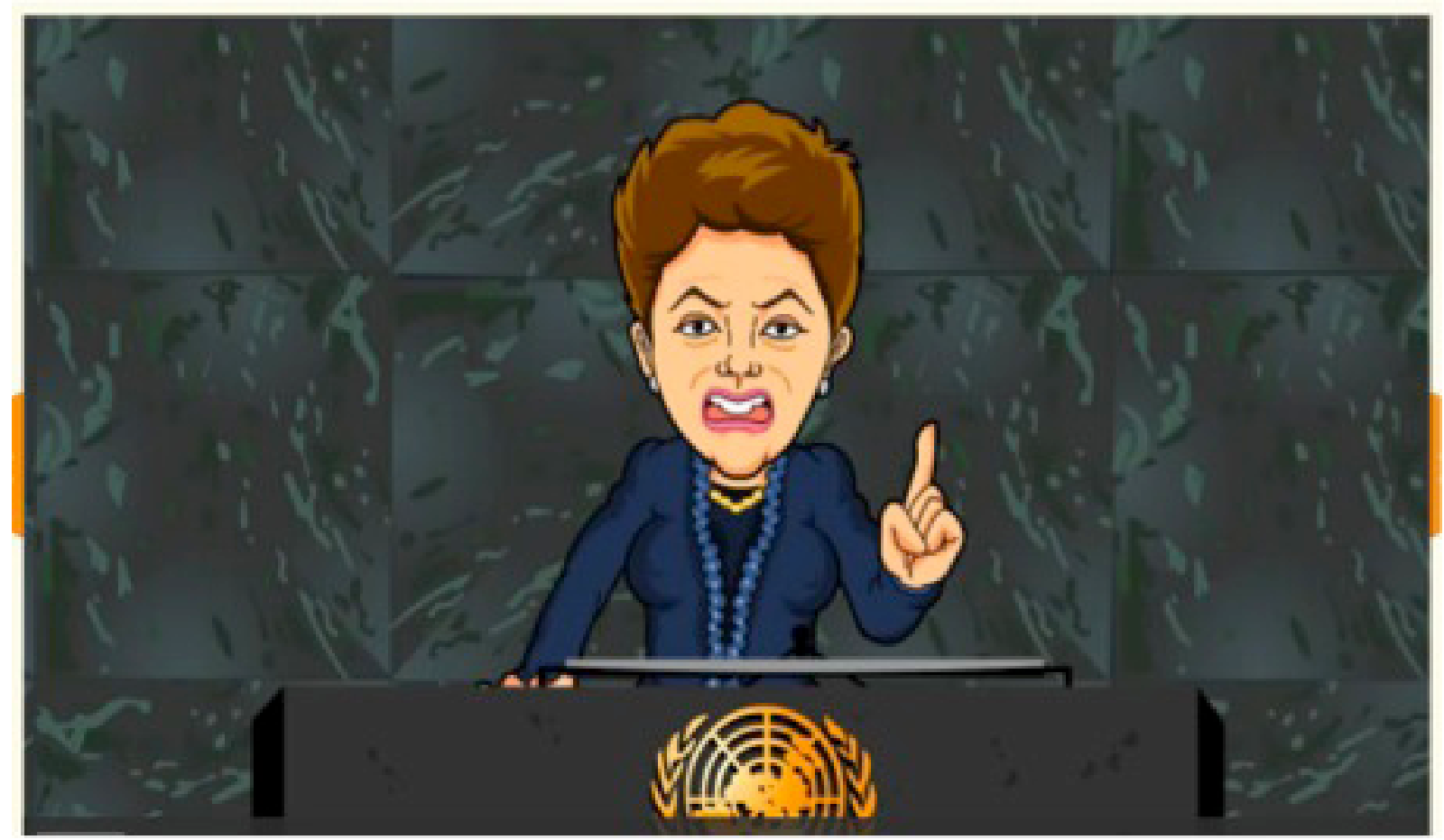

Figura 1: imagem obtida em:

<http://charges.uol.com.br/2013/09/25/cotidiano-espionagem-e-roubo/>.

Acesso em 30/09/2014.

Com relação às modalizações, deve-se destacar que encontramos pouca presença de modalizadores na charge. Isso ocorre porque o texto é assertivo, ou seja, o tom de crítica é distinto daquele proferido no discurso da presidente na abertura da $68^{\circ}$ Assembleia-Geral das Nações Unidas. A charge, caracterizada por elementos que subvertem um texto base, apresenta suas críticas de maneira categórica e transgressiva, o que acaba gerando o humor.

Observamos a presença da modalização lógica em "Não temos medo de que o conteúdo vaze porque estou certa de que não acharão nada que nos incrimine". A expressão em negrito exprime um julgamento sobre a veracidade daquilo que é enunciado, apresentando a inocência do governo brasileiro como certa. No entanto, é importante observar que essa modalização está a serviço de uma ironia e compõe um trecho que, como analisamos, é polifônico.

Todos esses mecanismos, como Bronckart explica, contribuem para a coerência pragmática do texto, ou seja, esclarecem os posicionamentos e avaliações tomadas num texto. No caso da charge, essas estratégias demonstram e levam o leitor à adoção de um único ponto de vista, que deflagra uma imagem negativa da situação política do país. A charge, nesse sentido, colabora para reproduzir ainda mais a divulgação negativa e irônica da grande mídia em relação ao discurso proferido pela 
Linha D'Água (Online), São Paulo, v. 29, n. 1, p. 201-224, jun. 2016

presidente, salientando apenas a questão da espionagem e silenciando as outras questões por ela abordadas. Nesse sentido, é importante o trabalho com diferentes textos a fim de que o leitor perceba que toda construção textual carrega em si elementos verbais e não-verbais que direcionam ideologicamente a leitura para a perspectiva que se quer salientar. Uma análise linguístico-enunciativa compreendida no contexto em que o texto foi produzido é imprescindível para a formação de um leitor deveras crítico e não reprodutor de um único ponto de vista.

\section{Considerações finais}

Com base nas análises acima apresentadas, destaca-se primeiramente o modo como a Presidente da República articulou seu discurso: a princípio, afirma estar satisfeita pela presença de um representante de Antígua e Barbuda na condução dos trabalhos da Assembleia, mostrando-se prestativa ao fornecer-lhe apoio permanente de seu governo, que vale destacar aqui, ser um país de economia estável e um paraíso fiscal ${ }^{4}$. Em seguida, o tom do discurso político muda para a questão do ataque terrorista em Nairóbi, Quênia ${ }^{5}$, com expressão de condolências ao país e forte menção ao combate ao terrorismo. Aproveitando o ensejo, a presidente expõe a problemática da espionagem norte-americana, deixando evidente a gravidade do problema e exigindo um posicionamento da ONU com relação a esse acontecimento. Sabendo que Barack Obama discursaria após a presidente e que a questão da espionagem foi apresentada logo após o ataque terrorista, percebe-se que o tom usado parece igualar a ação norte-americana ao mesmo nível daqueles que cometeram o atentado à cidade queniana.

Além disso, as mudanças nos conteúdos temáticos e as escolhas lexicais usadas nesse texto refletem um firme posicionamento com relação aos temas abordados por parte da Presidente da República, além de nos indicar que ora ela se mostra como a chefe de Estado que é capaz de oferecer apoio a um outro país, condolências ao outro, incitar aquele que violou sua privacidade como pessoa e chefe de estado, ora, devido ao posicionamento do Brasil no cenário econômico atual, como aquela detentora do direito de exigir retratação e de fornecedora de meios de proteger o seu país contra tal ato.

4 Fonte: https://www.pwc.pt/pt/guia-fiscal/2013/paraisos-fiscais.jhtml. Acesso em: 12 set. 2014.

5 Fonte: http://gl globo.com/mundo/noticia/2013/09/quenia-busca-respostas-apos-ataque-terrorista-em-shopping-de-nairobi.html. Acesso em: 12 set. 2014. 
Os posicionamentos acima ficam ainda mais evidentes por meio da análise das vozes, em que se verificou que a voz da autora, a Presidente da República, alterou-se ao longo do discurso nos mostrando que ela não falava apenas de sua posição política, mas também em nome de uma nação, em nome daqueles que sofreram a invasão pela espionagem, como aquela que combateu a opressão e daquela que entende as afrontas jurídicas causadas por tal ato.

Ao contrário, com a análise das vozes na charge eletrônica, vimos que a imagem humorística que se constrói da presidente no discurso na ONU é desfeita por meio de um jogo conflitante de vozes, que leva o leitor a recuperar os problemas da política brasileira e corrobora com a divulgação negativa do discurso pela grande mídia, principalmente em relação à questão da espionagem norte-americana, levando o leitor à adoção de um ponto de vista específico.

As vozes de ambos os textos evidenciam que nossos discursos se constroem por meio das diferentes instâncias que nos compõem como falantes de uma língua e, no caso dessas vozes em específico, fazem com que o discurso político atinja diferentes interlocutores e criem diferentes efeitos de sentido, devido aos diferentes posicionamentos que ele assume.

Quanto às modalizações, elas nos apontaram que a espionagem foi vista de maneira negativa pela presidente (apreciativa), pois ao longo de seu discurso clama por ações contra esse ato (pragmática), não deixando de destacar o quanto esse acontecimento fere com a liberdade de um país e de seus cidadãos (deôntica).

A análise do discurso da presidente, bem como a da charge, apontaram ainda a importância da determinação do contexto sócio-histórico de produção desses textos, visto que o conhecimento dos acontecimentos que permearam a escrita deles justifica as escolhas linguísticas e discursivas que os compõem, além de nos fazer compreender a quem eles se dirigem e quais suas intenções.

Para finalizar, acreditamos ser necessário pontuarmos duas questões relevantes ao leitor deste texto: a primeira, para o leitor não familiarizado com o quadro epistemológico aqui adotado, que o interacionismo sociodiscursivo, apoiado na escola vigotskiana, postula que as formas de conhecimento "são construídas no quadro de atividades sempre inicialmente coletivas e sempre mediadas pelas interações verbais" (Bronckart, 1999, p. 106). Assim, o ISD sustenta que as atividades coletivas mediadas pelas práticas de linguagem são primeiras e é no quadro das avaliações sociodiscursivas (linguageiras) da atividade que as ações são delimitadas. E é pela apropriação e interiorização dessas propriedades sociossemióticas dessas avaliações que se constroem pessoas capazes de agir. Assim, pensamento consciente emerge como um produto da ação e da linguagem (Bronckart, 1999). O quadro de análise proposto pelo ISD nos possibilitou ver as avaliações postas em evidência na charge eletrônica 
Linha D'Água (Online), São Paulo, v. 29, n. 1, p. 201-224, jun. 2016

e a distorção em relação ao discurso proferido pela presidente e a importância dessa leitura na perspectiva do ISD sobre o agir humano.

A segunda questão, para todo o leitor e linguista, é a posição dos estudiosos de linguagem em não tratar de questões políticas em seus estudos, seja para manter o caráter "científico" de seus estudos (RAJAGOLAPAN, 2013), seja por não querer se envolver em questões "polêmicas". Nesse sentido, postulamos a necessidade de um ensino de língua pautado em evidenciar os efeitos de sentido causados pela linguagem usada nos textos pertencentes a diferentes gêneros textuais (e aqui vale ressaltar que não faltam exemplos veiculados e noticiados pela mídia brasileira que possibilitam essas análises em sala de aula por alunos não tão conscientes dos usos da língua nesse contexto). Ações políticas são medidas intervencionistas (RAJAGOLAPAN, 2013) e o professor pode ser o grande ator- mediador-interventor desse processo na sala de aula.

\section{Referências}

ACHARD, Pierre. [et al.]. Papel da memória. Campinas, São Paulo: Pontes Editores, 2010.

BRONCKART, Jean Paul. Os mecanismos enunciativos. In: Atividades de linguagem, textos e discursos. Por um interacionismo sociodiscursivo. 2 ed. São Paulo: EDUC, 2007 [1999].

BUTLER, Daniela Barbosa. A imagem esfacelada do professor: um estudo em textos de revistas. 2009. 179 f. Dissertação (Mestrado em Linguística Aplicada e Estudos da Linguagem) - Pontifícia Universidade Católica de São Paulo, São Paulo, 2009.

CHARAUDEAU, Patrick \& MAINGUENEAU, Dominique. Dicionário de análise do discurso. São Paulo: Contexto, 2004.

COSTA, Adriano Ribeiro. Mecanismos enunciativos: análise das vozes e modalizações em artigos científicos. Rios Eletrônica. Revista Científica da FASETE, ano 6, n. 6, dezembro de 2012.

Disponível em: <http://www.fasete.edu.br/revistarios/media/revistas/2012/mecanismos_enunciativos.pdf>. Acesso em 30 de set. de 2013.

CRISTOVÃO, Vera Lúcia Lopes. Sequências didáticas para o ensino de línguas. In: DIAS, Reinildes, CRISTOVÃO, Vera Lúcia. (Orgs.). O livro didático de língua estrangeira: múltiplas perspectivas. Campinas: Mercado das Letras, 2009. 
Linha D'Água (Online), São Paulo, v. 29, n. 1, p. 201-224, jun. 2016

DAHER, Maria del Carmen F. González. Discursos presidenciais de $1^{\circ}$ de maio: a trajetória de uma prática discursiva, 2000.291f. Tese (Doutorado em Linguística Aplicada ao Ensino de Línguas) Pontifícia Universidade Católica, São Paulo, 2000.

DUCROT, Oswald. Esboço de uma teoria polifônica da enunciação. In: O dizer e o dito. Tradução de Eduardo Guimarães. Campinas, São Paulo: Pontes, 1987. p. 161-222.

FLORES, Valdir do Nascimento; TEIXEIRA, Marlene. Introdução à linguística da enunciação. São Paulo: Contexto, 2005.

KOCH, Ingedore Villaça. O texto e a construção dos sentidos. São Paulo: Contexto, 1997.

. A intertextualidade. In: . Introdução à linguística textual: trajetórias e grandes temas. 2 ed. São Paulo: Editora Martins Fontes, 2009.

KOCH, Ingedore Villaça; BENTES, Anna. Christina; CAVALCANTE, Mônica Magalhães. Intertextualidade diálogos possíveis. São Paulo: Cortez, 2007.

MAGALHÃES, Amarildo Pinheiro. Sentido, história e memória em charges eletrônicas do governo Lula: Os domínios do interdiscurso. UEM (Dissertação de Mestrado), Maringá, 2006.

MACHADO, Anna Rachel. A perspectiva interacionista sociodiscursiva de Bronckart. In: MEURER, José Luiz; BONINI, Adair; MOTTA-ROTH, Désirée. Gêneros: teorias, métodos, debates. São Paulo: Parábola Editorial, 2005.

PÉREZ, Mariana. Com a palavra, o professor: vozes e representaçôes docentes à luz do interacionismo sociodiscursivo. 2009. 153f. Dissertação (Mestrado em Linguística e Ensino) - Universidade Federal da Paraíba, João Pessoa, 2009.

PINTO, Celi Regina Jardim. Elementos para uma análise de discurso politico. Revista Barbaroi, n. $24,2006$.

Disponível em <http://online.unisc.br/seer/index.php/barbaroi/article/view/821/605>. Acesso em 15 de agosto de 2014.

RAJAGOPALAN, Kanavillil. Política de ensino de línguas no Brasil: história e reflexões prospectivas. In: MOITA LOPES, Luiz Paulo da. (Org.) Linguistica Aplicada na modernidade recente:festschrift para Antonieta Celani. São Paulo: Parábola, 2013, p. 143-162.

ROMUALDO, Edson Carlos. Charge jornalistica: intertextualidade e polifonia. Um estudo de charges da Folha de S. Paulo. Maringá: Eduem, 2000. 
Linha D'Água (Online), São Paulo, v. 29, n. 1, p. 201-224, jun. 2016

SILVA, Carla Messias Ribeiro. O modelo didático do gênero comentário jornalístico radiofônico: uma necessária etapa para a intervenção didática. 2009. 187 f. Dissertação (Mestrado em Linguística Aplicada e Estudos da Linguagem). Pontifícia Universidade Católica de São Paulo, São Paulo, 2009.

Recebido: $15 / 03 / 2016$

Aprovado: 21/05/2016 